\title{
PEMBINAAN SOFTSKILL KOMUNIKASI BAHASA INGGRIS GENERASI MUDA PEKANBARU DALAM MENGHADAPI GLOBALISASI
}

\author{
Luerdi $^{1)}$, Zaldi Harfal ${ }^{2}$ \\ 1) Program Studi Ilmu Hubungan Internasional, Universitas Abdurrab \\ 2) Program Studi Pendidikan Bahasa Inggris, Universitas Riau \\ Surel: luerdi@univrab.ac.id
}

\begin{abstract}
ABSTRAK
Artikel ini bertujuan menggambarkan bagaimana generasi muda di Pekanbaru dapat dimotivasi dan dipersiapkan untuk mengambil manfaat dari globalisasi melalui kegiatan pengabdian masyarakat dalam bentuk pembinaan soft skill komunikasi bahasa. Bahwa Indonesia khususnya Pekanbaru masih tertinggal dalam hal profisiensi komunikasi bahasa Inggris di tengah-tengah arus globalisasi yang tak mungkin dihindari menjadi pendorong pelaksanaan kegiatan ini. Program ini dilaksanakan dalam bentuk pelatihan yang menyenangkan yang menekankan pada keterlibatan aktif peserta mencakup semua aspek kompetensi komunikasi. Program ini menunjukkan beberapa capaian positif seperti kemunculan kesadaran, peningkatan kompetensi dasar, penumbuhan kepercayaan diri serta kepuasan dari orang tua peserta. Program ini, atau semacamnya di kemudian hari, diharapkan semakin memberikan manfaat kepada masyarakat, menggerakkan pembangunan dan meningkatan sumber daya manusia di kota Pekanbaru.
\end{abstract}

Kata kunci: pemberdayaan, soft skill, komunikasi, genarasi muda, globalisasi

\begin{abstract}
This article aims to describe how young generation in Pekanbaru could be motivated and prepared in order to take advantages of globalization through a community service program called the soft skill empowerment of language communication. The fact that Indonesia, especially Pekanbaru, is still left behind in term of English proficiency amid inevitable globalization encouraged such program. The program was conducted in the form of fun training which emphasized the participants' active involvement overseeing all aspects of communication competency. The program has shown some positive outcomes such as raising awareness, improving basic competence, gaining selfconfidence and securing parents' satisfaction. The program, or others which are alike in the future, is supposed to benefit community, generate development and improve the city human resource.
\end{abstract}

Key words: empowerment, soft skill, communication, young generation, globalization. 


\section{PENDAHULUAN}

Kegiatan ini bertujuan untuk membina genarasi tunas yang ada di Pekanbaru dalam rangka mewujudkan generasi yang mampu berdadaptasi di tengah-tengah arus globalisasi. Kegiatan ini termasuk dalam kategori sektor publik yang memfokuskan pada pembinaan kemampuan dasar berupa softskill komunikasi bahasa Inggris sehari-hari bagi anak-anak dan remaja.

Globalisasi telah menjadikan dunia seperti desa global (global village) di mana perkembangan dunia dapat dirasakan diseluruh pelosok negara. Hal ini didukung pula oleh kemajuan teknologi transportasi dan informasi di mana pergerakan manusia, barang dan jasa serta kemudahan mengakses informasi dapat dilakukan secara cepat. Di sisi lain, globalisasi juga telah memaksa negara dan warganya untuk berdaptasi agar dapat mengambil manfaat dari kemajuan sehingga tidak tertinggal dari negara dan bangsa lain.

Globalisasi juga memberikan dampak di tingkat lokal yang menyentuh berbagai aspek kehidupan seperti pendidikan. Pendidikan saat ini diharapkan mampu menghasilkan insan yang beriman, bertaqwa, bermoral serta memiliki keahlian yang dapat berkontribusi pada pembangunan. Melalui pendidikan pula baik formal maupun non-formal, pembinaan kemampuan softskill bahasa asing khususnya bahasa Inggris dilakukan. Softskill komunikasi bahasa Inggris menjadi kebutuhan saat ini tidak hanya di dunia akademik tapi juga di dunia profesi, olahraga, hiburan, pariwisata dan pergaulan. Penguasaan bahasa Inggris juga membantu pengembangan dan peningkatan kualitas sumber daya manusia di tingkat lokal.

Indeks penguasaan bahasa Inggris (English Proficiency Index-EPI) Indonesia masih tertinggal dari negara-negara lain, baik dalam skala global maupun skala regional Asia. Berdasarkan riset yang dilakukan oleh EF Global (2018a), Indonesia menduduki peringkat 51 dengan kategori profisiensi rendah skala global dari 88 negara dan peringkat 13 dengan kategori profisiensi rendah dari 21 negara skala Asia. Perbandingan EPI Indonesia dengan negara-negara lain dapat dilihat dari tabel di bawah ini.

Tabel 1. Peringkat Regional Asia EPI (EF Global, 2018a)

\begin{tabular}{|l|l|l|l|l|}
\hline Very high & \multicolumn{1}{|c|}{ High } & \multicolumn{1}{c|}{ Moderate } & \multicolumn{1}{c|}{ Low } & \multicolumn{1}{c|}{ Very low } \\
\hline 01 Singapore & 02 Philipines & 04 India & 09 China & 17 Kazakhstan \\
& 03 Malaysia & 05 Hong Kong, & 10 Taiwan & 18 Myanmar \\
& & China & 11 Japan & 19 Afghanistan \\
& & 06 South Korea & 12 Pakistan & 20 Cambodia \\
& & 07 Vietnam & 13 Indonesia & 21 Uzbekistan \\
& & 08 Macau, China & 14 Sri Lanka & \\
& & & 15 Bangladesh & \\
& & & & \\
& & & & \\
\hline
\end{tabular}

Kecenderungan EPI Indonesia menurun dua tahun terakhir (2017 dan 2018) dengan kategori profisiensi rendah dibandingkan tahun 2016 dan tahun-tahun sebelumnya yang termasuk dalam kategori moderat. Kencendungan EPI Indonesia dari tahun ke tahun dapat dilihat dari tabel di bawah ini. 
Tabel 2. Peringkat Global EPI (EF Global, 2018a)

\begin{tabular}{|l|l|l|l|l|}
\hline \multicolumn{1}{|c|}{ Very high } & \multicolumn{1}{c|}{ High } & \multicolumn{1}{c|}{ Moderate } & \multicolumn{1}{c|}{ Low } & \multicolumn{1}{c|}{ Very low } \\
\hline 01 Sweden & 13 Poland & 28 India & 45 Georgia & 66 Iran \\
02 Netherlands & 14 Philippines & 29 Nigeria & 46 Chile & 67 Morocco \\
03 Singapore & 15 Switzerland & 30 Hong Kong, & 47 China & 68 Tunisia \\
04 Norway & 16 Romania & China & 48 Taiwan & 69 Honduras \\
05 Denmark & 17 Croatia & 31 South Korea & 49 Japan & 70 El Salvador \\
06 South Africa & 18 Serbia & 32 Spain & 50 Pakistan & 71 U.A.E. \\
07 Luxembourg & 19 Portugal & 33 Lebanon & 51 Indonesia & 72 Nicaragua \\
08 Finland & 20 Czech & 34 Italy & 52 Albania & 73 Turkey \\
09 Slovenia & Republic & 35 France & 53 Brazil & 74 Jordan \\
10 Germany & 21 Hungary & 36 Costa Rica & 54 Ethiopia & 75 Venezuela \\
11 Belgium & 22 Malaysia & 37 Dominican & 55 Guatemala & 76 Syria \\
12 Austria & 23 Greece & Republic & 56 Panama & 77 Azerbaijan \\
& 24 Slovakia & 38 Belarus & 57 Mexico & 78 Kuwait \\
& 25 Bulgaria & 39 Senegal & 58 Sri Lanka & 79 Oman \\
& 26 Lithuania & 40 Uruguay & 59 Peru & 80 Kazakhstan \\
& & 41 Vietnam & 60 Colombia & 81 Algeria \\
& & 42 Russia & 61 Bolivia & 82 Myanmar \\
& & 43 Ukraine & 62 Egypt & 83 Saudi Arabia \\
& & 44 Macau, China & 63 Bangladesh & 84 Afghanistan \\
& & & 64 Thailand & 85 Cambodia \\
& & & 65 Ecuador & 86 Uzbekistan \\
& & & 87 Iraq \\
& & & &
\end{tabular}

Tabel 3. Kecenderungan EPI Indonesia 2011-2018 (EF Global, 2018b)

\begin{tabular}{|c|c|c|c|c|c|c|c|c|}
\hline Year & $\mathbf{2 0 1 1}$ & $\mathbf{2 0 1 2}$ & $\mathbf{2 0 1 3}$ & $\mathbf{2 0 1 4}$ & $\mathbf{2 0 1 5}$ & $\mathbf{2 0 1 6}$ & $\mathbf{2 0 1 7}$ & $\mathbf{2 0 1 8}$ \\
\hline EPI & Very low & Low & Moderate & Moderate & Moderate & Moderate & Low & Low \\
& & & & & & & & \\
\hline $\begin{array}{c}\text { Ranking/ } \\
\text { Countries }\end{array}$ & $\# 34 /$ & $\# 27 /$ & $\# 25 /$ & $\# 28 /$ & $\# 32 /$ & $\# 32 /$ & $\# 39 /$ & $\# 51 /$ \\
\hline
\end{tabular}

Untuk tingkat lokal skala provinsi, Bali menduduki posisi tertinggi dengan kategori profisiensi moderat, kemudian diikuti oleh provinsi DKI Jakarta, DI Yogyakarta dan Jawa Timur (EF Global, 2018b). Dalam skala kota, Surabaya menduduki posisi tertinggi dengan kategori profisiensi moderat, kemudian diikuti oleh Bandung dan Yogyakarta (EF Global, 2018b). Riau dan Pekanbaru masih berada di luar kategori tersebut. Perbandingan EPI beberapa provinsi dan kota di Indonesia dapat dilihat dari tabel di bawah ini.

Tabel 4. Peringkat Provinsi EPI (EF Global, 2018b)

\begin{tabular}{|l|l|l|l|l|}
\hline Very high & High & \multicolumn{1}{c|}{ Moderate } & \multicolumn{1}{c|}{ Low } & \multicolumn{1}{c|}{ Very low } \\
\hline & & 01 Bali & 05 West Java & 10 South \\
& & 02 Jakarta & 06 Central Java & Sumatra \\
& & 03 Yogyakarta & 07 Banten & 11 South \\
& & 04 East Java & 08 East & Sulawesi \\
& & & Kalimantan & \\
& & & 09 North & \\
& & & & \\
\hline
\end{tabular}


Tabel 5. Peringkat Kota EPI (EF Global, 2018b)

\begin{tabular}{|l|l|l|l|l|}
\hline Very high & High & \multicolumn{1}{|c|}{ Moderate } & Low & Very low \\
\hline & & 01 Surabaya & 04 Tangerang & \\
& & 02 Bandung & & \\
& & 03 Yogyakarta & & \\
& & City & & \\
\hline
\end{tabular}

Dari penjelasan di atas, dapat dipahami bahwa EPI di Indonesia secara umum masih tergolong rendah. Sedangkan untuk tingkat lokal, data EPI menampakkan jurang yang tajam di mana daerah-daerah di Jawa dan Bali cenderung memiliki EPI yang lebih baik dibandingkan dengan daerah-daerah lain khususnya Riau dan Pekanbaru. Permasalahan ini juga diperkuat oleh masih rendahnya keinginan dan minat generasi muda untuk menguasai softskill ini. Sementara, penguasaan bahasa Inggris menjadi salah satu pendukung agar warga negara dapat mengambil manfaat dengan perkembangan dan kemajuan dunia yang tak terbendung hampir di semua bidang kehidupan. Bagi Riau dan Pekanbaru, EPI yang baik tentu seiring dengan kemajuan sumber daya manusia yang akan berkontribusi pada pembangunan daerah.

Dari analisa situasi di atas, ada beberapa masalah yang dapat diidentifikasi yaitu sebagai berikut:

1) Rendahnya tingkat penguasaan softskill komunikasi bahasa Inggris Indonesia secara global.

2) Adanya jurang penguasaan softskill komunikasi bahasa Inggris di tingkat lokal di mana daerah-daerah di Jawa dan Bali cenderung memiliki tingkat penguasaan yang lebih baik.

3) Rendahnya kesadaran dan keinginan genarasi muda Riau, khususnya Pekanbaru untuk menguasai softskill komunikasi bahasa Inggris di tengah-tengah arus globalisasi.

Kegiatan ini akan menjawab rumusan masalah berikut "Bagaimana upaya yang dapat dilakukan untuk menumbuhkan kesadaran dan meningkatkan softskill komunikasi dasar bahasa Inggris generasi muda di Pekanbaru?"

Kegiatan ini memiliki beberapa tujuan yaitu:

1) Tujuan umum:

Memberikan kesadaran kepada generasi muda melalui kegiatan pembinaan tentang pentingnya meningkatkan kemampuan komunikasi untuk membantu pemerintah melakukan pembangunan.

2) Tujuan khusus:

a) Memberikan kesadaran kepada dan mendorong generasi muda yang ada di Pekanbaru untuk meningkatkan kemampuan softskill komunikasi bahasa Inggris yang akan bermanfaat dalam kehidupan sehari-hari baik dalam pendidikan maupun dunia profesi.

b) Memfasilitasi generasi muda di Pekanbaru untuk belajar dan meingkatkan kemampuan dasar softskill komunikasi bahasa Inggris melalui kegiatan pembinaan.

c) Membantu pemerintah kota Pekanbaru dalam meningkatkan kualitas SDM lokal. 
Adapun manfaat yang diperoleh dari kegiatan ini adalah sebagai beikut:

1) Generasi muda di Pekanbaru memiliki keasadaran tentang pentingnya beradaptasi dan memilki kualitas SDM yang baik di tengah arus globalisasi yang tak terbendung.

2) Generasi muda di Pekanbaru memiliki kemampuan softskill komunikasi dasar bahasa Inggris yang bermanfaat dalam proses pendidikan mereka saat ini.

3) Munculnya kesadaran kolektif tentang tanggungjawab warga negara untuk berkontribusi dalam program pembangunan negara.

\section{TINJAUAN PUSTAKA}

1) Konsep Pembinaan

Literatur tentang pembinaan generasi muda dapat dilihat pada karya Tangdilintin. Tangdilintin (2018) mengungkapkan bahwa pembinaan merupakan pelayanan. Sebagai bentuk pelayanan, pembinaan merupakan bentuk keprihatinan aktif yang nyata dalam tindakan yang menjunjung tinggi harkat dan martabat generasi muda serta mengangkat harga diri dan kepercayaan diri mereka. Pembinaan selanjutnya akan menjadi pemberdayaan dengan beberapa tujuan yaitu (1) menyadarkan dan membebaskan; (2) memekarkan potensi dan membangun kepercayaan diri; (3) menumbuhkan keasadaran kritis yang membangun dan bertanggungjawab; dan (4) mendorong peran aktif secara sosial (Tangdilintin, 2018).

2) Konsep Komunikasi

Dalam Kamus Besar Bahasa Indonesia (Kemdikbud, 2018), komunikasi merupakan pengiriman dan penerimaan pesan atau berita antara dua orang atau lebih sehingga pesan yang dimaksud dapat dipahami. Sedangkan Louis Forsdale (dalam Ubaidillah, 2016) mendefinisikan komunikasi sebagai "the process by which system is established, maintained and altered by means of shared signals that operated according to rules." Berkaitan dengan azas-azas komunikasi, Ruben dan Stewart (dalam Ubaidillah, 2016) membagi komunikasi dalam empat azas yaitu (1) komunikasi adalah sebuah proses; (2) komunikasi terjadi dalam wilayah intrapersonal, interpersonal, kelompok, organisasi dan masyarakat; (3) komunikasi melibatkan penerimaan dan penciptaan pesan serta mengubahnya menjadi informasi yang dapat digunakan; dan (4) komunikasi membuat seseorang beradaptasi dengan orang lain dan lingkungan.

3) Konsep Globalisasi

Globalisasi dapat diartikan sebagai "the extension of social relations over the globe" yang telah memunculkan kecenderungan kemiripan dan keseragaman dari individu, kelompok dan sistem sosial yang telah melewati atau bahkan menghapuskan batas-batas tradisional negara (Perwita \& Yani, 2014). Dalam pengertian yang hampir sama, Malcom Waters (dalam Nurhaidah, 2015) berpendapat bahwa globalisasi adalah sebuah proses sosial yang berakibat pembatasan geografis pada keadaan sosial budaya menjadi kurang penting yang terjelma di dalam kesadaran orang. Sedangkan Selo Soemardjan, bapak Sosiologi Indonesia, berpendapat bahwa globalisasi adalah terbentuknya organisasi dan komunikasi antara masyarakat di seluruh dunia untuk mengikuti sistem dan kaidah yang sama (Nurhaidah, 2015). 


\section{METODE PELAKSANAAN}

Kegiatan ini dilaksanakan selama tiga bulan (Oktober-November 2018) mulai dari tahap perencanaan sampai tahap pelaporan Kegiatan ini dilaksanakan dalam bentuk pembinaan berkesinambungan yang merupakan perpaduan dari pelatihan dan praktek yang mengedepankan aspek kognitif dan motorik. Selain itu kegiatan ini juga menekankan pada aspek sosial seperti kerjasama, saling menghargai dan bertanggungjawab. Kegiatan ini berorientasi pada hasil sehingga evaluasi menjadi bagian penting dalam kegiatan ini.

Kegiatan ini diikuti oleh generasi muda (siswa dan siswi) dari 10 sekolah yang ada di Pekanbaru. Adapun penanggungjawab kegiatan beserta deskripsi tugas yang dilaksanakan selama kegiatan adalah sebagai berikut:

Tabel 6. Penanggungjawab Kegiatan dan Deskripsi Tugas

\begin{tabular}{|c|l|l|l|}
\hline No & \multicolumn{1}{|c|}{ Nama } & \multicolumn{1}{c|}{ Peran } & \multicolumn{1}{c|}{ Deskripsi Tugas } \\
\hline 1 & Luerdi, S.IP., M.Si & Instruktur utama & $\begin{array}{l}\text { Memberikan } \\
\text { pembinaan (pelatihan) } \\
\text { kepada peserta, } \\
\end{array}$ \\
& Zaldi Harfal, S.Pd., & & $\begin{array}{l}\text { melakukan evaluasi } \\
\text { dan rekomendasi. }\end{array}$ \\
\hline 2 & An.TESOL & & $\begin{array}{l}\text { Mempersiapkan } \\
\text { kebutuhan selama } \\
\text { kegiatan berlangsung }\end{array}$ \\
& Rossa Rossi Lina & Asisten instruktur & \\
\hline
\end{tabular}

\section{HASIL DAN PEMBAHASAN}

Selama kegiatan kami berupaya memberikan berbagai materi praktis kepada peserta sehingga peserta mampu merasakan manfaat dari kegiatan ini secara nyata. Peserta tidak hanya mendengarkan pemaparan dari para instruktur, tapi berperan aktif selama kegiatan berlangsung. Peserta juga diwajibkan untuk mempraktekkan apa yang telah dijelaskan dan didemontrasikan oleh instruktur. Partisipasi peserta dalam kegiatan ini mencakup berbagai aspek komunikasi dasar seperti mendengar, berbicara dan menulis. Selama kegiatan, instruktur juga memberikan berbagai bentuk permainan (games) yang menarik agar peserta tidak merasa bosan dan tetap tertarik pada kegiatan pengabdian ini.

Pada bagian ini kami akan memaparkan hasil (output) yang diperoleh selama melaksanakan pengabdian ini, seperti (1) tumbuhnya kesadaran peserta tentang penguasaan komunikasi sedari usia muda; (2) perubahan kemampuan dasar komunikasi peserta; (3) peningkatan kepercayaan diri peserta, serta (4) respon positif dari orang tua.

1) Kesadaran.

Kegiatan ini menargetkan sisi personal peserta di mana peserta memahami bahwa mereka memerlukan softskill komunikasi dasar bahasa Inggris sedari awal pada usia muda. Mempelajari kemampuan komunikasi sewaktu muda memiliki kelebihan berupa mudahnya menyerap informasi dengan cepat, mudahnya mengingat serta mengucapkan berbagai frase dan ungkapan harian dengan cepat. 
Kesadaran yang dimaksud dapat dilihat dari kesungguhan peserta untuk memenuhi tuntutan kehadiran tanpa beban.

2) Kemampuan dasar.

Kegiatan ini telah menghasilkan perubahan kemampuan dasar komunikasi peserta yang mencakup aspek mendengar, berbicara dan menulis. Sebelum mengikuti kegiatan ini, peserta memiliki kemampuan komunikasi dasar yang sangat minim terlihat dari dari hasil wawancara yang dilakukan di awal pertemuan. Namun, selama kegiatan peserta telah menampakkan perubahan melalui skema evaluasi rutin yang dilakukan oleh instruktur. Walaupun peserta kegiatan memiliki tingkat kemampuan yang berbeda, secara umum mereka telah berhasil menunjukkan perubahan kemampuan selama kegiatan berlangsung. Peserta mulai memahami pesan yang disampaikan oleh instruktur, merespon dan mengungkapkan fikiran mereka serta menuliskan pesan-pesan sederhana.

3) Kepercayaan diri.

Kegiatan ini tidak hanya menekankan pada kemampuan berkomunikasi tapi juga aspek kepercayaan diri peserta dalam berkomunikasi. Kepercayaan diri merupakan syarat penting agar apa yang dipahami oleh peserta dapat diungkapkan dengan baik dan dimengerti oleh orang lain. Kegiatan ini telah membantu meningkatkan kepercayaan diri peserta yang dapat dilihat dari kesediaan peserta untuk mempraktekkan apa yang telah disampaikan oleh instruktur. Bersamaan dengan peningkatan kemampuan dan kepercayaan diri, peserta juga mampu melakukan kerjasama team work serta menghargai keanekaragaman latar belakang diantara peserta.

4) Respon positif orang tua.

Kami menyadari tujuan kegiatan ini tidak akan dapat tercapai dengan maksimal tanpa adanya dukungan dari orang tua peserta mengingat usia peserta yang muda. Dukungan orang tua di rumah terhadap pentingnya kegiatan ini menjadi pendorong kehadiran dan pencapaian peserta. Orang tua peserta menyadari pentingnya menguasai kemampuan komunikasi dasar bagi bagi anak-anak mereka sedari awal. Selama kegiatan berlangsung, orang tua mengapresiasi kegiatan ini karena dirasakan bermanfaat sebagai bekal bagi anak-anak mereka, tidak hanya kebutuhan pendidikan saat ini tapi juga kebutuhan di masa yang akan datang. 


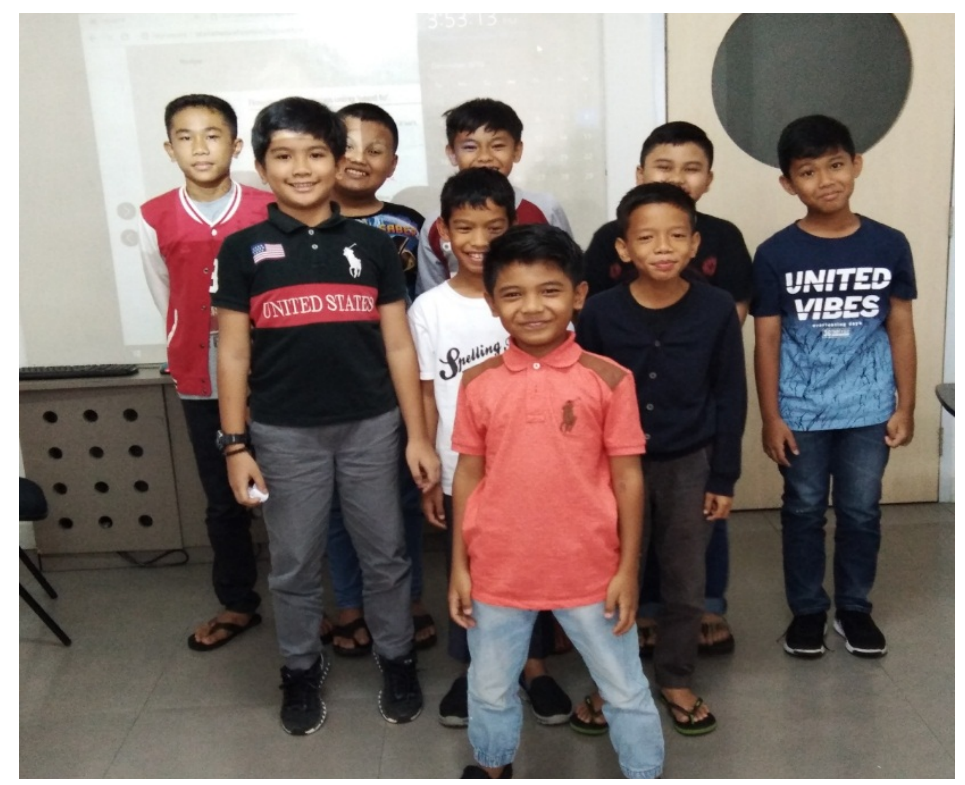

Gambar 1. Peserta Kegiatan Pembinaan

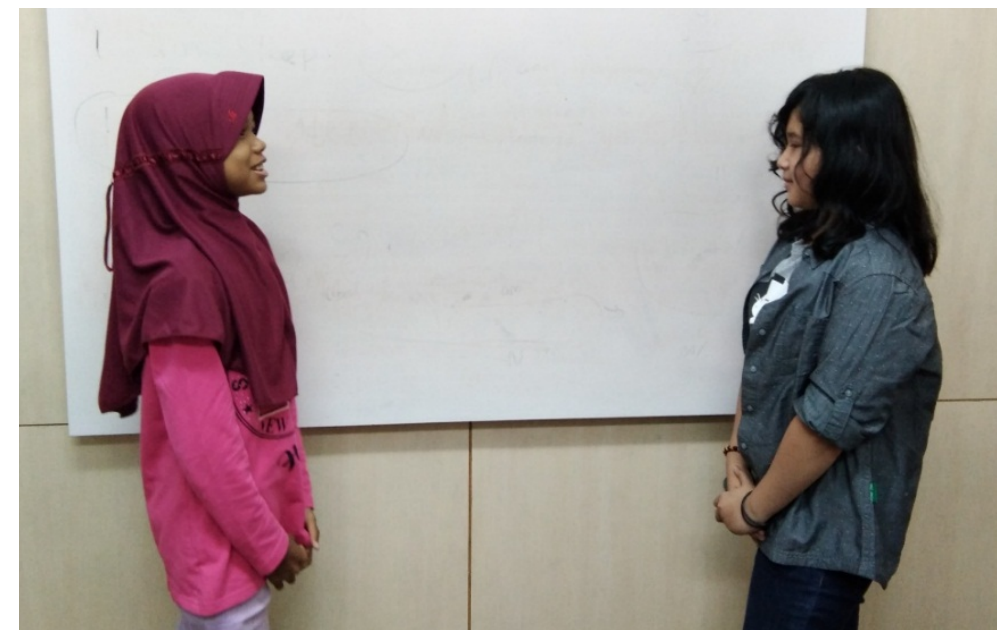

Gambar 2. Aktifitas Peningkatan Kepercayaan Diri Peserta

\section{KESIMPULAN}

Kegiatan ini diikuti dengan antusias oleh peserta terlihat dari tingkat kehadiran dan hasil evaluasi pencapaian selama kegiatan. Selama kegiatan, kami tidak melihat adanya kesulitan yang serius dari peserta dalam memahami materi-materi yang disampaikan. Berkat persiapan yang baik serta dukungan seluruh stake holder, kegiatan ini dapat dilaksanakan dengan baik dan memperoleh berbagai capaian yang telah direncanakan seperti tumbuhnya kesadaran, perubahan kemampuan dasar, peningkatan kepercayaan diri serta respon positif dari orang tua peserta.

Secara umum kegiatan pengabdian ini diharapkan dapat meningkatkan kualitas SDM lokal dalam menghadapi arus globalisasi sehingga mampu mengambil manfaat dari berbagai peluang yang ada. Untuk jangka panjang, kegiatan ini dan kegiatan lain yang serupa diharapkan dapat memperkecil jurang penguasaan bahasa asing khususnya bahasa Inggris antara generasi muda di Pekanbaru dengan daerah-daerah lain di Indonesia. 


\section{DAFTAR PUSTAKA}

[5]. EF Global. (2018a). EF English Proficiency Index: Global Ranking of Countries and Regions. Retrieved from https://www.ef.com/wwen/epi/

[6]. EF Global. (2018b). EF English Proficiency Index: Indonesia. Retrieved from https://www.ef.com/wwen/epi/regions/asia/indonesia/

[7]. Kemdikbud. (2018). KBBI Daring. Retrieved from https://kbbi.kemdikbud.go.id/entri/komunikasi

[8]. Nurhaidah, M.I.M. (2015). Dampak Pengaruh Globalisasi bagi Kehidupan Bangsa Indonesia. Jurnal Persona Dasar, 3(3), 1-14. Retrieved from http://www.jurnal.unsyiah.ac.id/PEAR/article/download/7506/6178

[9]. Perwita, A.A.B., \& Yani, Y.M. (2014). Pengantar Ilmu Hubungan Internasional. PT. Remaja Rosdakarya. Bandung.

[10]. Tangdilintin. (2008). Pembinaan Generasi Muda. Kanisius. Yogyakarta.

[11]. Ubaidillah, A. (2016). Konsep dasar Komunikasi untuk Kehidupan. Al Ibtida', 4(2), 30-54. Retrieved from http://ejournal.kopertais4.or.id/mataraman/index.php/alibtida/article/view/2987 